\title{
A Comparative Study of Nonlinear Control Schemes for Induction Motor Operation Improvement
}

\author{
Yassine Zahraoui ${ }^{\mathrm{a}, 1, *}$, Mohamed Akherraz ${ }^{\mathrm{a}, 2}$, Alfian Ma'arif ${ }^{\mathrm{b}, 3}$ \\ ${ }^{a}$ Mohammed 5 University, Mohammadia School of Engineering, Rabat, Morocco \\ ${ }^{\mathrm{b}}$ Universitas Ahmad Dahlan, Yogyakarta, Indonesia \\ ${ }^{1}$ zahraoui.yassin@gmail.com; ${ }^{2}$ akherraz@emi.ac.ma; ${ }^{3}$ alfian.maarif@te.uad.ac.id \\ * Corresponding Author
}

\section{ARTICLE INFO}

\section{Article History}

Received November 30, 2021

Revised December 15, 2021

Accepted December 20, 2021

\section{Keywords}

Induction Motor Drive;

Nonlinear Control;

Integral Backstepping Approach;

Sliding Mode Theory;

Extended Kalman Filter

\section{ABSTRACT}

In the objective of improving the performance of induction motor operation and ensuring a robust control against different uncertainties and external disturbances, especially at low-speed regions, this research highlights the main features of two nonlinear control techniques. First, the control design is based on the backstepping approach (BSA) with integral action, and then the sliding mode control (SMC) theory. The BSA principle is to define successive causal relations in order to construct the control law in a recursive and systematic way. This allows overcoming the obstacle of the higher-order system's dimension. SMC is designed to drive and then constrain the system state to lie within a neighborhood of the switching surface, this provides very strong and inherent robustness to the resulting controllers. The main reason behind developing the nonlinear control techniques is to ensure a decoupled control of the machine. Besides, it guarantees the stability of the overall system by tracking the speed reference with the fewest static error. Moreover, as the sensorless control increases the reliability and decreases the cost of the control system, an extended Kalman filter is implemented to improve speed and flux observation. The simulations of all the discussed results have been obtained by MATLAB/Simulink.

This is an open access article under the CC-BY-SA license

\section{Introduction}

Nowadays, AC machines have replaced DC machines in industrial applications because of their advantages, such as, the reliability and the lack of commutator and brushes which make them able to work under unfriendly conditions. The most popular AC machines are induction motors (IMs) and permanent magnet synchronous motors (PMSMs). They are used in various industrial applications, electric vehicles, and drives. The squirrel-cage induction motor drive, in particular, is widely used due to its reduced cost and lower maintenance requirement [1].

Most physical systems are by nature non-linear and multivariate, they have inherently interconnected non-linearity in their internal dynamics, particularly the induction motor drives. They have control problems in speed adjustable contrary to the DC motor due to some reasons: the high order of internally coupled non-linearity, some state variables are not directly measurable, parameters variation because of environmental effects, and external load perturbations during its operation. The use of conventional approaches such as the proportional-integral-differential (PID) controllers to under- 
stand the behavior of those systems by analytical techniques can be inadequate [2][3]. Even at the initial stages of establishing the mathematical model, the existence of discrepancies between the real and the developed model for control design is so potential. This has led to an intense interest in the development of the so-called nonlinear control theory which seeks to solve this problem [4].

Among the most important developed non-linear control strategies in the last few decades: the backstepping approach (BSA) and the sliding mode theory (SMC). BSA is a non-linear control approach used to transform a non-linear system into an equivalent linear one, then the possibility of applying a conventional controller design. This algorithm provides good behavior in steady and dynamic states. In addition, it offers also an exact decoupling between the system variables [5][6]. The application of the aforementioned non-linear techniques for the improvement of basic electrical drive control strategies like vector control has been presented in several works. The combining of BSA and vector control has been done by Krstic, Kanellakopoulos, and Kokotovic for high performance. In [7] similar modified strategies are applied to SVM-FOC controlled drive. SMC is a particular type of variable structure control (VSC). The first concepts of SMC appeared in Russian literature (The former Soviet Union) in the 1950s and were developed by Emelyanov in the 1960s. Later, Utkin has written an English summary of papers on sliding mode control. The main features of this approach are the dynamic behavior of the system which may be tailored by a particular choice of the switching function. Furthermore, the structure is independent of the object parameters which makes the closed-loop response becomes totally insensitive to a particular class of uncertainty in the system, this provides very strong and inherent robustness to the resulting controllers [8]. These techniques are applied for the direct torque control (DTC) schemes as for vector control (FOC). DTC offers an excellent torque response using fewer model parameters than FOC. Due to its simplicity and very fast response, it can be so applicable for high-performance drive applications [9][10][11][12].

Kalman filter can overcome the non-linear state observation by using a linearized approximation, where, the stochastic continuous-time system must be expressed in the discrete form in order to fit with the structure of extended Kalman filter (EKF) [13]. The process of observation of the EKF is given in two stages, prediction and filtering. The prediction stage is aimed to obtain the next predicted states and predicted state-error covariance, while in the filtering stage, the next estimated states are obtained as the sum of the next predicted states and a correction term [14]. However, the high degree of complexity of the EKF structure and the high system orders cause higher computational requirements. Thus, additional challenges and problems are introduced, such as the reduction of dynamic performance and the increase of harmonics. Nevertheless, the development of new processors technology (DSPs and FPGAs) solves this problem due to the powerful calculation processing [15].

\section{Induction Motor Mathematical Model}

The state-space mathematical model of a three-phase squirrel-cage induction motor drive in $d-q$ reference frame is given by [16][17]:

$$
\left\{\begin{array}{l}
\dot{X}=\mathbf{A} X+\mathbf{B} U \\
Y=\mathbf{C} X
\end{array}\right.
$$

Where $X, U$ and $Y$ are the state, the input, and the output vectors respectively:

$$
\begin{aligned}
& X=\left[i_{d s} i_{q s} \phi_{d r} \phi_{q r}\right]^{t} ; U=\left[u_{d s} u_{q s}\right]^{t} ; Y=\left[i_{d s} i_{q s}\right]^{t} \\
& \mathbf{A}=\left[\begin{array}{cccc}
-\lambda & 0 & \frac{K}{T_{r}} & K \omega_{r} \\
0 & -\lambda & -K \omega_{r} & \frac{K}{T_{r}} \\
\frac{L_{m}}{T_{r}} & 0 & -\frac{1}{T_{r}} & -\omega_{r} \\
0 & \frac{L_{m}}{T_{r}} & \omega_{r} & -\frac{1}{T_{r}}
\end{array}\right] ; \mathbf{B}=\left[\begin{array}{cc}
\frac{1}{\sigma L_{s}} & 0 \\
0 & \frac{1}{\sigma L_{s}} \\
0 & 0 \\
0 & 0
\end{array}\right] ; \mathbf{C}=\left[\begin{array}{cccc}
1 & 0 & 0 & 0 \\
0 & 1 & 0 & 0
\end{array}\right]
\end{aligned}
$$


With: $\lambda=\frac{R_{s}}{\sigma L_{s}}+\frac{1-\sigma}{\sigma T_{r}} ; K=\frac{1-\sigma}{\sigma L_{m}} ; \sigma=1-\frac{L_{m}^{2}}{L_{s} L_{r}} ; T_{r}=\frac{L_{r}}{R_{r}}$

The electromechanical power is written as:

$$
P_{e}=p \frac{M}{L_{r}}\left(\phi_{d r} i_{q s}-\phi_{q r} i_{d s}\right) \Omega_{r}
$$

The electromagnetic torque is obtained by dividing the electromechanical power $P_{e}$ by $\Omega_{r}$, hence:

$$
T_{e}=p \frac{M}{L_{r}}\left(\phi_{d r} i_{q s}-\phi_{q r} i_{d s}\right)
$$

The rotor motion is expressed by:

$$
J \frac{d \Omega_{r}}{d t}=T_{e}-T_{L}-f \Omega_{r}
$$

Where $J$ is the motor inertia, $T_{L}$ is the load torque, and $f$ is the friction coefficient. Fig. 1 shows the induction motor state-space mathematical model.

\section{Backstepping Control Approach}

This control method proposes a recursive and systematic synthesis method destined to the nonlinear system classes that have a parametric form. At the first step, the first virtual command is calculated from the tracking error, which will be used in the second stage as a reference signal for the next state. This operation is repeated until reaching the $n^{\text {th }}$ stage that allows generating the command that will be applied to the system [18]. Fig. 2 shows the backstepping approach control strategy.

\subsection{Application to Induction Motor Control}

The backstepping basic idea is to recursively choose some appropriate state functions as virtual command outputs for first-order subsystems of the global system. This implicates that the backstepping application is divided into many steps. In each step, an extended Lyapunov function is associated with the goal to guarantee the whole system's stability [19].

Step 1: In this step, the speed and the rotor flux are a regulation variables, the regulation errors $e_{1}$ and $e_{2}$ are:

$$
\begin{aligned}
& e_{1}=\Omega_{r}^{*}-\Omega_{r} \\
& e_{2}=\phi_{r}^{*}-\hat{\phi}_{r}
\end{aligned}
$$

The errors dynamics are given by:

$$
\begin{gathered}
\dot{e}_{1}=\dot{\Omega}_{r}^{*}-\eta \phi_{r} i_{q s}+\frac{T_{l}}{J}+\frac{f}{J} \Omega_{r} \\
\dot{e}_{2}=\dot{\phi}_{r}^{*}+\frac{1}{T_{r}} \phi_{r}-\frac{M}{T_{r}} i_{d s}
\end{gathered}
$$

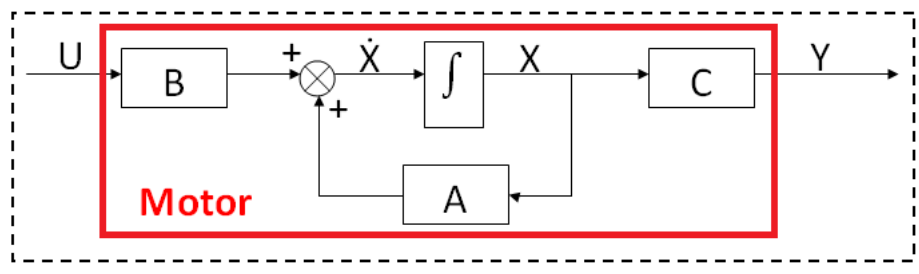

Fig. 1. Input, state, and output vector of induction motor 


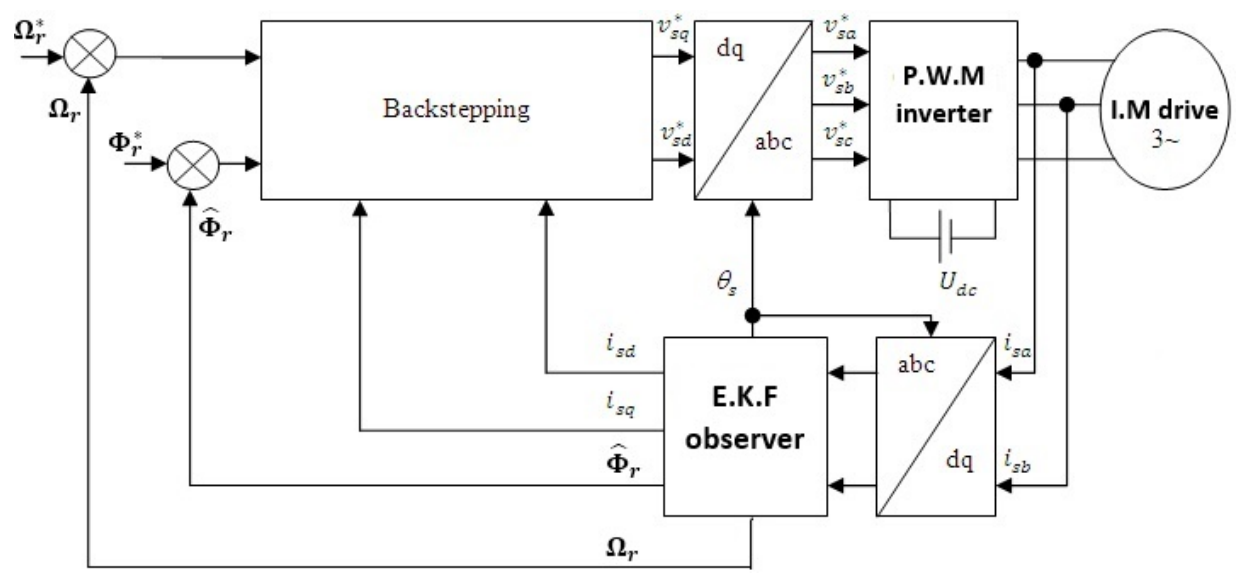

Fig. 2. Induction motor backstepping approach control

The objective now is to converge the two errors to zero, $i_{d s}$ and $i_{q s}$ are then chosen as a virtual commands for the systems (7) and (8). For that reason, the next candidate Lyapunov function is chosen as:

$$
V_{1}=\frac{1}{2}\left[e_{1}^{2}+e_{2}^{2}\right]
$$

Its derivative is:

$$
\dot{V}_{1}=-k_{1} e_{1}^{2}-k_{2} e_{2}^{2}+e_{1}\left[k_{1} e_{1}+\dot{\Omega}_{r}^{*}-\eta \phi_{r} i_{q s}+\frac{T_{l}}{J}+\frac{f}{J} \Omega_{r}\right]+e_{2}\left[k_{2} e_{2}+\dot{\phi}_{r}^{*}+\frac{1}{T_{r}} \phi_{r}-\frac{M}{T_{r}} i_{d s}\right]
$$

Where $k_{1}$ and $k_{2}$ are positive constants. In order that the Lyapunov function derivative $\dot{V}_{1}$ be negative, the virtual commands that represent the stabilization functions can be chosen as follow:

$$
\begin{gathered}
i_{d s}^{*}=\frac{T_{r}}{M}\left[k_{2} e_{2}+\dot{\phi}_{r}^{*}+\frac{1}{T_{r}} \phi_{r}\right] \\
i_{q s}^{*}=\frac{1}{\eta \phi_{r}}\left[k_{1} e_{1}+\dot{\Omega}_{r}^{*}+\frac{T_{l}}{J}+\frac{f}{J} \Omega_{r}\right]
\end{gathered}
$$

We then get:

$$
\dot{V}_{1}=-k_{1} e_{1}^{2}-k_{2} e_{2}^{2} \leq 0
$$

The virtual commands in (11) and (12) are chosen to satisfy the tracking objectives and are also considered as references for the next step.

Step 2: By defining the currents $i_{d s}$ and $i_{q s}$ as the new regulation objectives considered as virtual commands for this step [20], the new regulation errors $e_{3}$ and $e_{4}$ will be defined as:

$$
\begin{gathered}
e_{4}=i_{d s}^{*}-i_{d s}=\frac{T_{r}}{M}\left[k_{2} e_{2}+\dot{\phi}_{r}^{*}+\frac{1}{T_{r}} \phi_{r}\right]-i_{d s} \\
e_{3}=i_{q s}^{*}-i_{q s}=\frac{1}{\eta \phi_{r}}\left[k_{1} e_{1}+\dot{\Omega}_{r}^{*}+\frac{T_{l}}{J}+\frac{f}{J} \Omega_{r}\right]-i_{q s}
\end{gathered}
$$

As consequence, the errors dynamics (7) and (8) can be expressed as:

$$
\begin{aligned}
& \dot{e}_{1}=-k_{1} e_{1}+\eta \phi_{d} e_{3} \\
& \dot{e}_{2}=-k_{2} e_{2}+\frac{M}{T_{r}} e_{4}
\end{aligned}
$$


Also, the errors dynamics are given as:

$$
\begin{aligned}
& \dot{e}_{3}=\dot{i}_{q s}^{*}-\dot{i}_{q s}=\dot{i}_{q s}^{*}-\Psi_{1}-\frac{1}{\sigma L_{s}} v_{q s} \\
& \dot{e}_{4}=\dot{i}_{d s}^{*}-\dot{i}_{d s}=\dot{i}_{d s}^{*}-\Psi_{2}-\frac{1}{\sigma L_{s}} v_{d s}
\end{aligned}
$$

Where:

$$
\begin{gathered}
\Psi_{1}=-\gamma i_{q s}-\eta \Omega_{r} \phi_{d}-p \Omega_{r} i_{s d}-\frac{M}{T_{r}} \frac{i_{s d} i_{q s}}{\phi_{d}} \\
\Psi_{2}=-\gamma i_{d s}+\frac{\eta}{T_{r}} \phi_{d}+p \Omega_{r} i_{q s}+\frac{M}{T_{r}} \frac{i_{d s}^{2}}{\phi_{d}}
\end{gathered}
$$

Let's consider the next Lyapunov candidate function:

$$
V_{1}=\frac{1}{2}\left[e_{1}^{2}+e_{2}^{2}+e_{3}^{2}+e_{4}^{2}\right]
$$

Its derivative is:

$$
\dot{V}_{2}=-k_{1} e_{1}^{2}-k_{2} e_{2}^{2}-k_{3} e_{3}^{2}-k_{4} e_{4}^{2}+e_{3}\left[k_{3} e_{3}+\dot{i}_{q s}^{*}-\Psi_{1}-\frac{1}{\sigma L_{s}} v_{q s}\right]+e_{4}\left[k_{4} e_{4}+\dot{i}_{d s}^{*}-\Psi_{2}-\frac{1}{\sigma L_{s}} v_{d s}\right]
$$

Where $k_{3}$ and $k_{4}$ are positive constants. We deduce then the new command laws:

$$
\begin{aligned}
& v_{q s}^{*}=\sigma L_{s}\left[k_{3} e_{3}+\dot{i}_{q s}^{*}-\Psi_{1}\right] \\
& v_{d s}^{*}=\sigma L_{s}\left[k_{4} e_{4}+\dot{i}_{d s}^{*}-\Psi_{2}\right]
\end{aligned}
$$

Which make the extended Lyapunov function derivative $\dot{V}_{2}$ negative:

$$
\dot{V}_{2}=-k_{1} e_{1}^{2}-k_{2} e_{2}^{2}-k_{3} e_{3}^{2}-k_{4} e_{4}^{2} \leq 0
$$

Proposition 1: If the speed and flux regulators which have been synthesized with the backstepping method are respectively (24) and (25), so the speed and flux will asymptotically converge to their desired values.

\subsection{Integral Backstepping Approach}

We define the speed tracking error as:

$$
z_{1}=e_{1}+\delta_{1} \int e_{1} d t=\Omega_{r}^{*}-\Omega_{r}+\delta_{1} \int\left(\Omega_{r}^{*}-\Omega_{r}\right) d t
$$

With $\delta_{1}$ a positive constant and $\delta_{1} \int e_{1} d t$ is the integral action added to the backstepping command in order to ensure the convergence of the speed tracking error to zero [21]. The error dynamic is given as:

$$
\dot{z}_{1}=\dot{e}_{1}+\delta e_{1}=\dot{\Omega}_{r}^{*}-\eta \phi_{r} i_{q s}+\frac{T_{l}}{J}+\frac{f}{J} \Omega_{r}+\delta_{1} e_{1}
$$

Let's consider the candidate Lyapunov function:

$$
V_{1}=\frac{1}{2} z_{1}^{2}
$$

Its derivative is given as:

$$
\dot{V}_{1}=-k_{1} z_{1}^{2}+z_{1}\left[k_{1} z_{1}+\dot{\Omega}_{r}^{*}-\eta \phi_{r} i_{q s}+\frac{T_{l}}{J}+\frac{f}{J} \Omega_{r}+\delta_{1} e_{1}\right]
$$


Basing on the backstepping method and in goal to ensure the speed tracking stability [22], the virtual command $i_{q s}^{*}$ is given by the following equation:

$$
i_{q s}^{*}=\frac{1}{\eta \phi_{r}}\left[k_{1} z_{1}+\dot{\Omega}_{r}^{*}+\frac{T_{l}}{J}+\frac{f}{J} \Omega_{r}+\delta_{1} e_{1}\right]
$$

We then get:

$$
\dot{V}_{1}=-k_{1} z_{1}^{2} \leq 0
$$

The state $i_{q s}^{*}$ is used as an intermediate command to guarantee the stability of the whole system. The derivative of $z_{3}$ is given by:

$$
\dot{z}_{3}=\dot{i}_{s q}^{*}-\dot{i}_{q s}=\frac{1}{\eta \phi_{r}}\left[k_{1} z_{1}+\dot{\Omega}_{r}^{*}+\frac{T_{l}}{J}+\frac{f}{J} \Omega_{r}+\delta_{1} e_{1}\right]-\dot{i}_{q s}
$$

Let's consider the following extended candidate Lyapunov function:

$$
V_{2}=V_{1}+\frac{1}{2} z_{3}^{2}
$$

Its derivative is:

$$
\dot{V}_{2}=-k_{1} z_{1}^{2}-k_{3} z_{3}^{2}+z_{3}\left[k_{3} z_{3}+\dot{i}_{q s}^{*}-\Psi_{1}-\frac{1}{\sigma L_{s}} v_{q s}\right]
$$

By choosing the command law $v_{s q}$ as:

$$
v_{q s}^{*}=\sigma L_{s}\left[k_{3} z_{3}+\dot{i}_{q s}^{*}-\Psi_{1}\right]
$$

We will find that:

$$
\dot{V}_{2}=-k_{1} z_{1}^{2}-k_{3} z_{3}^{2} \leq 0
$$

\section{Sliding Mode Control Design}

In general, J.J. Slotine proposed an equation form to determine the sliding surface which ensure variable convergence to its desired value [23]:

$$
S(x)=\left(\frac{d}{d t}+\lambda\right)^{n-1} e(x)
$$

$e(x)=x^{*}-x$ : variable gap to be adjusted, $\lambda$ : strictly positive coefficient, $n$ : relative degree equal to the number of times to derive the output to get the suitable command.

Fig. 3 shows the sliding mode control strategy.

\subsection{Speed Regulator Synthesis}

By choosing $n=1$ in J.J. Slotine general equation (38), the speed sliding surface is defined by [24]:

$$
S\left(\Omega_{r}\right)=\Omega_{r}^{*}-\Omega_{r}
$$

Its derivative is:

$$
\dot{S}\left(\Omega_{r}\right)=\dot{\Omega}_{r}^{*}-\dot{\Omega}_{r}=\dot{\Omega}_{r}^{*}-\eta \phi_{r} i_{s q}+\frac{T_{l}}{J}+\frac{f}{J} \Omega_{r}
$$

By introducing the command current $i_{q s}^{*}=i_{q s_{e q}}+i_{q s_{n}}$ in equation (40), we get:

$$
\dot{S}\left(\Omega_{r}\right)=\dot{\Omega}_{r}^{*}-\eta \phi_{r d} i_{q s_{e q}}-\eta \phi_{r} i_{q s_{n}}+\frac{T_{l}}{J}+\frac{f}{J} \Omega_{r}
$$




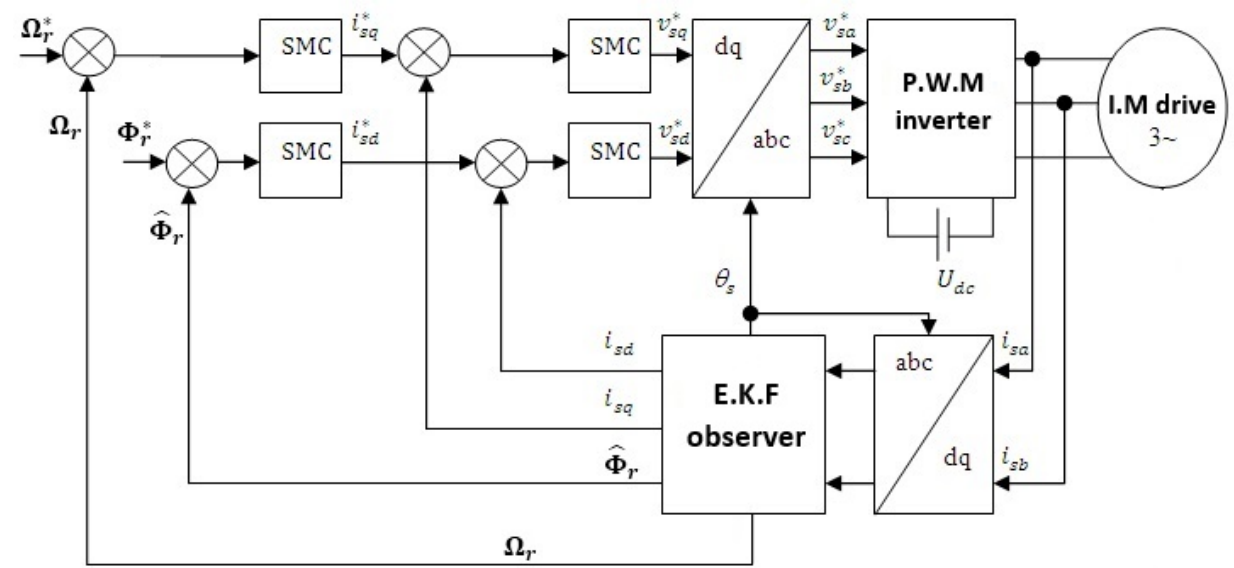

Fig. 3. Induction motor sliding mode control strategy

During the sliding mode and steady state, $S\left(\Omega_{r}\right)=0, \dot{S}\left(\Omega_{r}\right)=0$ and $i_{q s_{n}}=0$, we then get the equivalent command expression $i_{q s_{e q}}$ :

$$
i_{q s_{e q}}=\frac{1}{\eta \phi_{r}}\left(\dot{\Omega}_{r}^{*}+\frac{T_{l}}{J}+\frac{f}{J} \Omega_{r}\right)
$$

During the convergence mode, the discontinued command form $i_{q s_{n}}$ must satisfy the condition

$$
\dot{S}\left(\Omega_{r}\right) S\left(\Omega_{r}\right)<0 .
$$

By substituting expression of $i_{s q_{e q}}$ in (41), we find:

$$
\dot{S}\left(\Omega_{r}\right)=-\eta \phi_{r} i_{q s_{n}}
$$

The discontinued command form is put as:

$$
i_{q s_{n}}=K_{\Omega} \operatorname{sat}\left(\frac{S(\Omega)}{\epsilon_{\Omega}}\right)
$$

\subsection{Flux Regulator Synthesis}

Let $S\left(\phi_{r}\right)$ be the rotor flux sliding surface:

$$
S\left(\phi_{r}\right)=\phi_{r}^{*}-\phi_{r}
$$

Its derivative is:

$$
\dot{S}\left(\phi_{r}\right)=\dot{\phi}_{r}^{*}-\dot{\phi}_{r}
$$

By replacing the flux expression in (46), $\dot{S}\left(\phi_{r}\right)$ is given by:

$$
\dot{S}\left(\phi_{r}\right)=\dot{\phi}_{r}^{*}+\frac{1}{T_{r}} \phi_{r}-\frac{M}{T_{r}} i_{d s}
$$

By introducing the command current $i_{d s}^{*}=i_{d s_{e q}}+i_{d s_{n}}$ in equation (47), we get:

$$
\dot{S}\left(\phi_{r}\right)=\dot{\phi}_{r}^{*}+\frac{1}{T_{r}} \phi_{r}-\frac{M}{T_{r}} i_{d s_{e q}}-\frac{M}{T_{r}} i_{d s_{n}}
$$

During the sliding mode and steady state, $S\left(\phi_{r}\right)=0, \dot{S}\left(\phi_{r}\right)=0$ and $i_{d s_{n}}=0$, where we get the equivalent command expression $i_{d s_{e q}}$ :

$$
i_{d s_{e q}}=\frac{T_{r}}{M}\left(\dot{\phi}_{r}^{*}+\frac{1}{T_{r}} \phi_{r}\right)
$$


During the convergence mode, the discontinued command action $i_{s d_{n}}$ must satisfy the condition $\dot{S}\left(\phi_{r}\right) S\left(\phi_{r}\right)<0$ [25]. By substituting the expression of $i_{d s_{e q}}$ in (48), we find:

$$
\dot{S}\left(\phi_{r}\right)=-\frac{M}{T_{r}} i_{d s_{n}}
$$

The discontinued command is then put as:

$$
i_{d s_{n}}=K_{\phi} \operatorname{sat}\left(\frac{S\left(\phi_{r}\right)}{\epsilon_{\phi_{r}}}\right)
$$

\subsection{Current Regulators Synthesis}

Let's consider $S\left(i_{d s}\right)$ and $S\left(i_{q s}\right)$ the sliding surfaces of currents $i_{d s}$ and $i_{q s}$ respectively:

$$
\begin{aligned}
& S\left(i_{d s}\right)=i_{d s}^{*}-i_{d s} \\
& S\left(i_{q s}\right)=i_{q s}^{*}-i_{q s}
\end{aligned}
$$

By deriving the surfaces $S\left(i_{d s}\right), S\left(i_{q s}\right)$ and replacing the expressions of currents $i_{d s}$ and $i_{q s}, \dot{S}\left(i_{d s}\right)$ and $\dot{S}\left(i_{q s}\right)$ can then be written as:

$$
\begin{aligned}
& \dot{S}\left(i_{d s}\right)=\dot{i}_{d s}^{*}+\gamma i_{d s}-\frac{\eta}{T_{r}} \phi_{r}-\omega_{s} i_{q s}-\frac{1}{\sigma L_{s}} v_{d s} \\
& \dot{S}\left(i_{q s}\right)=\dot{i}_{q s}^{*}+\gamma i_{q s}+\eta \omega_{r} \phi_{r}+\omega_{s} i_{d s}-\frac{1}{\sigma L_{s}} v_{q s}
\end{aligned}
$$

By introducing the command voltages $v_{d s}^{*}=v_{d s_{e q}}+v_{d s_{n}}$ and $v_{q s}^{*}=v_{q s_{e q}}+v_{q s_{n}}$ in equations (54) and (55) respectively, we get:

$$
\begin{aligned}
& \dot{S}\left(i_{d s}\right)=\dot{i}_{d s}^{*}+\gamma i_{d s}-\frac{\eta}{T_{r}} \phi_{r}-\omega_{s} i_{q s}-\frac{1}{\sigma L_{s}} v_{d s_{e q}}-\frac{1}{\sigma L_{s}} v_{d s_{n}} \\
& \dot{S}\left(i_{q s}\right)=\dot{i}_{q s}^{*}+\gamma i_{q s}+\eta \omega_{r} \phi_{r}+\omega_{s} i_{d s}-\frac{1}{\sigma L_{s}} v_{q s_{e q}}-\frac{1}{\sigma L_{s}} v_{q s_{n}}
\end{aligned}
$$

During the sliding mode and steady state, $S\left(i_{d s}\right)=0, \dot{S}\left(i_{d s}\right)=0, v_{d s_{n}}=0, S\left(i_{q s}\right)=0, \dot{S}\left(i_{q s}\right)=0$ and $v_{q s_{n}}=0$, where we get the equivalent command expression $v_{d s_{e q}}$ and $v_{q s_{e q}}$ respectively:

$$
\begin{aligned}
& v_{d s_{e q}}=\sigma L_{s}\left(i_{d s}^{*}+\gamma i_{d s}-\frac{\eta}{T_{r}} \phi_{r}-\omega_{s} i_{q s}\right) \\
& v_{q s_{e q}}=\sigma L_{s}\left(i_{q s}^{*}+\gamma i_{q s}+\eta \omega_{r} \phi_{r}+\omega_{s} i_{d s}\right)
\end{aligned}
$$

During the convergence mode, the discontinued command action $v_{d s_{n}}$ and $v_{q s_{n}}$ must satisfy the conditions $\dot{S}\left(i_{d s}\right) S\left(i_{d s}\right)<0$ and $\dot{S}\left(i_{q s}\right) S\left(i_{q s}\right)<0$ [26]. By substituting the expressions of $v_{s d_{e q}}$ and $v_{s q_{e q}}$ in (58) and (59) respectively, we find:

$$
\begin{aligned}
& \dot{S}\left(i_{d s}\right)=-\frac{1}{\sigma L_{s}} v_{d s_{n}} \\
& \dot{S}\left(i_{q s}\right)=-\frac{1}{\sigma L_{s}} v_{q s_{n}}
\end{aligned}
$$

We then put respectively:

$$
\begin{aligned}
& v_{d s_{n}}=K_{i d} \operatorname{sat}\left(\frac{S\left(i_{d s}\right)}{\epsilon_{i d}}\right) \\
& v_{q s_{n}}=K_{i q} \operatorname{sat}\left(\frac{S\left(i_{q s}\right)}{\epsilon_{i q}}\right)
\end{aligned}
$$




\section{Extended Kalman Filter Algorithm for Induction Motor State Observation}

One of the methods which are used for rotor flux or motor speed estimation is the extended Kalman filter. Kalman filter is a non-linear closed-loop observer whose gain matrix is variable. In each computing step, the Kalman filter predicts the new values of motor state variables (stator currents, rotor flux, and speed). This prediction is performed either by minimizing the noise effects and parameters modeling errors or by the way of genetic algorithms [27].

The first prediction technique is used in simulations in this paper. The noises are assumed white, Gaussian, and uncorrelated with the estimated states [28]. Considering the process noise $w$ and the measurement noise $v$, the dynamic behaviour of the induction motor can be given by the following system:

$$
\begin{gathered}
\dot{x}=\mathbf{f}(\mathbf{x}, \mathbf{u})+w \\
y=h(x)+v
\end{gathered}
$$

Where: $\mathbf{f}(\mathbf{x}, \mathbf{u})=\left[\begin{array}{c}-\gamma i_{s \alpha}+\frac{\mu}{T_{r}} \phi_{r \beta}+\mu \omega_{r} \phi_{r \beta}+\frac{1}{\sigma L_{s}} u_{s \beta} \\ -\gamma i_{s \beta}-\mu \omega_{r} \phi_{r \alpha}+\frac{\mu}{T_{r}} \phi_{r \beta}+\frac{1}{\sigma L_{s}} u_{s \beta} \\ \frac{L_{m}}{T_{r}} u_{s \alpha}-\frac{1}{T_{r}} \phi_{r \alpha}-\omega_{r} \phi_{r \beta} \\ \frac{L_{m}}{T_{r}} u_{s \beta}+\omega_{r} \phi_{r \alpha}-\frac{1}{T_{r}} \phi_{r \beta}\end{array}\right]$

and $h(x)=\left[\begin{array}{ll}i_{\alpha s} & i_{\beta s}\end{array}\right]^{t}$

The covariance matrices $\mathrm{Q}$ and $\mathrm{R}$ of these noises are defined as follow:

$$
Q=\operatorname{cov}(w)=E\left\{w w^{t}\right\} ; R=\operatorname{cov}(v)=E\left\{v v^{t}\right\}
$$

The rotor speed can be estimated then by the following EKF algorithm from the above dynamic model [29][30].

- Prediction of state variables:

$$
\hat{x}_{k+1 \mid k}=f\left(x_{k \mid k}, u_{k}\right)
$$

- Estimation of error covariance matrix:

$$
P_{k+1 \mid k}=F_{k} P_{k \mid k} F_{k}^{t}+Q
$$

Where

$$
\mathbf{F}_{\mathbf{k}}=\left[\begin{array}{ccccc}
1-T_{s} \gamma & 0 & \frac{T_{s} \mu}{T_{r}} & T_{s} \mu \omega_{r} & T_{s} \mu \phi_{r \beta} \\
0 & 1-T_{s} \gamma & -T_{s} \mu \omega_{r} & \frac{T_{s} \mu}{T_{r}} & -T_{s} \mu \phi_{r \alpha} \\
\frac{T_{s} L_{m}}{T_{r}} & 0 & 1-\frac{T_{s}}{T_{r}} & -T_{s} \omega_{r} & -T_{s} \phi_{r \beta} \\
0 & \frac{T_{s} L_{m}}{T_{r}} & T_{s} \omega_{r} & 1-\frac{T_{s}}{T_{r}} & T_{s} \phi_{r \alpha} \\
0 & 0 & 0 & 0 & 1
\end{array}\right]
$$

- Kalman filter gain:

$$
K_{k+1}=P_{k+1 \mid k} H_{k}^{t}\left[H_{k} P_{k+1 \mid k} H_{k}^{t}+R\right]^{-1}
$$

Where:

$$
\mathbf{H}_{\mathbf{k}}=\frac{\partial h\left(x_{k}\right)}{\partial x_{k}}
$$




$$
\mathbf{H}_{\mathbf{k}}=\left[\begin{array}{lllll}
1 & 0 & 0 & 0 & 0 \\
0 & 1 & 0 & 0 & 0
\end{array}\right]
$$

- Estimation of state variables:

$$
\hat{x}_{k+1 \mid k+1}=\hat{x}_{k+1 \mid k}+K_{k+1}\left(y_{k+1}-H_{k} \hat{x}_{k+1 \mid k}\right)
$$

- Update of error covariance matrix:

$$
P_{k+1 \mid k+1}=P_{k+1 \mid k}-K_{k+1} H_{k} P_{k+1 \mid k}
$$

Fig. 4 shows the extended Kalman filter state-space mathematical model.

\section{Results and Discussion}

In this section, the two non-linear control techniques have been designed and simulated. And in order to show the system robustness against the external perturbation, a load torque of 10 N.m is applied at a specific instant and lately removed.

\subsection{Test at Low-Speed Region}

In this test, the speed reference is a ramp of low value $10 \mathrm{rad} / \mathrm{s}$ changing rotational direction at $t=1 \mathrm{~s}$. The load torque is applied at $t_{1}=0.5 \mathrm{~s}$ and removed at $t_{2}=1.4 \mathrm{~s}$.

Fig. 5 shows a performance comparison between the integral backstepping control and the conventional control-based PI controllers: PI in the left and BSA with integral action in the right. The simulation results show that the BSA technique exhibits good dynamics and high robustness at startup. There are significant and noticeable differences in the transient response. The speed error between the reference and the real speed in the non-linear version is very small and does not exceed $0.2 \mathrm{rad} / \mathrm{s}$. It can be clearly seen that the load disturbance does not affect the mechanical speed. The speed control loop rejects it quickly. The DFOC-BSA technique showed perfect speed tracking with less error compared to the conventional vector control-based PI controllers.

\subsection{Test at High-Speed Region}

In this test, the speed reference is a ramp of high value $80 \mathrm{rad} / \mathrm{s}$ then $160 \mathrm{rad} / \mathrm{s}$. The load torque this time is applied at $t_{1}=0.7 \mathrm{~s}$ and removed at $t_{2}=1.7 \mathrm{~s}$.

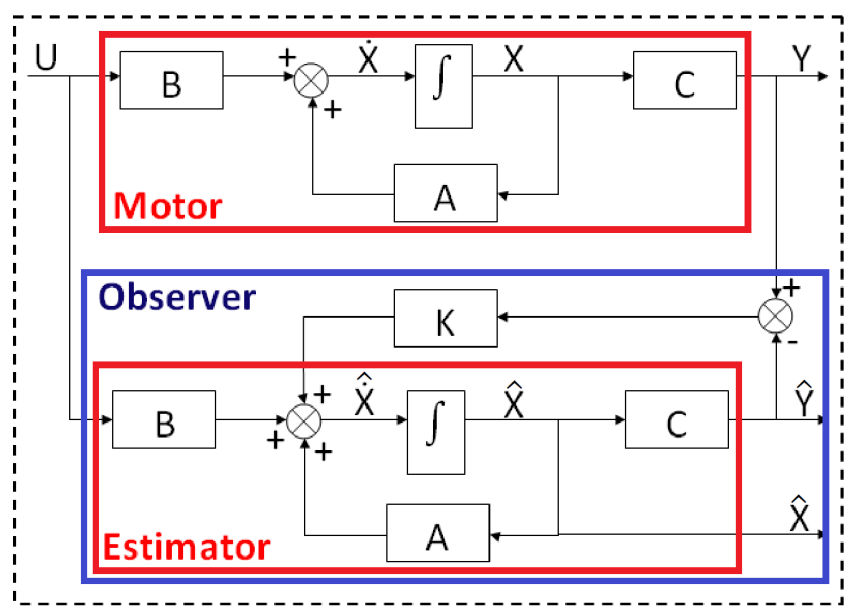

Fig. 4. Input, state, and output vector of the extended Kalman filter 
Fig. 6 demonstrates a performance comparison between the sliding mode control and the conventional control: PI in the left and SMC in the right. The simulation results show that the SMC technique has good dynamics and high robustness at the starting-up. There are large and significant differences in the transient response. The speed error between the reference and the real speed is very small and does not exceed $0.2 \mathrm{rad} / \mathrm{s}$. It can be clearly seen that the load disturbance does not affect the mechanical speed.

\section{Conclusion}

In this paper, two well-known nonlinear techniques applied to the squirrel-cage induction motor drive control are designed and simulated. The obtained simulation results have confirmed the efficiency and the precision of these proposed control strategies during the sudden load torque, low and high-speed regions. The two control laws have confirmed better control and robustness against the load torque disturbance, the key is the good choice of the extended candidate Lyapunov functions that allow a quick variables convergence. Besides, the extended Kalman filter for rotor speed and flux observation has been successfully applied to the sensorless control scheme.

Author Contribution: All authors contributed equally to the main contributor to this paper. All authors read and approved the final paper.

Funding: This research received no external funding.

Acknowledgment: The author would like to thank to everyone that help to finish this article.

Conflicts of Interest: The authors declare no conflict of interest.

\section{Appendix}

Table 1 lists the rated power and parameters of the induction motor used in simulation.

Table 1. Rated power and parameters of the used machine in simulation

\begin{tabular}{|c|c|}
\hline Rated power & $3 \mathrm{~kW}$ \\
\hline Rated speed & $1440 \mathrm{rpm}$ \\
\hline Pair pole & 2 \\
\hline Frequency & $50 \mathrm{~Hz}$ \\
\hline Line voltage & $220 / 380 \mathrm{~V}$ \\
\hline Phase current & $12.5 / 7.2 \mathrm{~A}$ \\
\hline Stator resistance & $2.2 \Omega$ \\
\hline Rotor resistance & $2.68 \Omega$ \\
\hline Stator inductance & $0.229 \mathrm{H}$ \\
\hline Rotor inductance & $0.229 \mathrm{H}$ \\
\hline Mutual inductance & $0.217 \mathrm{H}$ \\
\hline Moment of inertia & $0.047 \mathrm{~kg} . \mathrm{m}^{2}$ \\
\hline Viscous friction coefficient & $0.004 \mathrm{N.s} / \mathrm{rad}$ \\
\hline
\end{tabular}

\section{References}

[1] F. Altun, S. A. Tekin, S. Gürel, and M. Cernat, "Design and Optimization of Electric Cars. A Review of Technological Advances," in 2019 8th International Conference on Renewable Energy Research and Applications (ICRERA), Nov. 2019, pp. 645-650, https://doi.org/10.1109/ICRERA47325.2019.8996516.

[2] Z. Ullah, I. Sami, R. Asghar, B. Azeem, S. M. Ali, U. Farid, B. Khan, C. A. Mehmood, and A. Haider, "A Comparative study of Linear and Nonlinear Control Schemes for AC Induction Machines," in 2018 


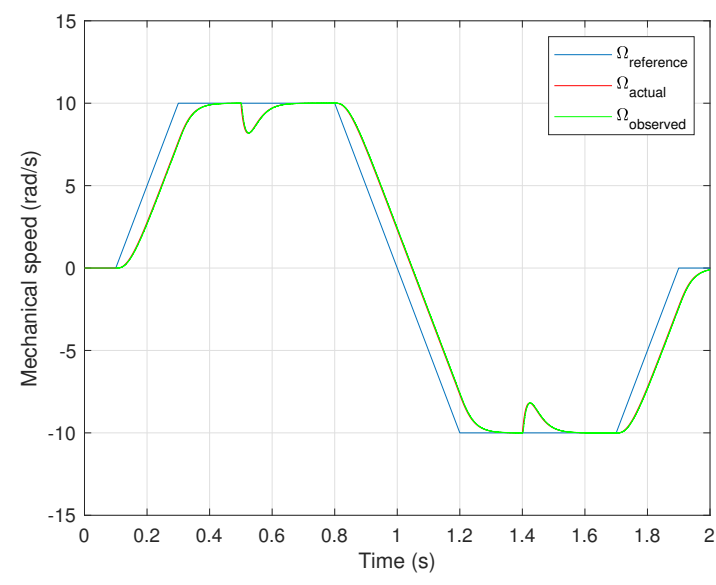

(a) DFOC-PI: Mechanical speed

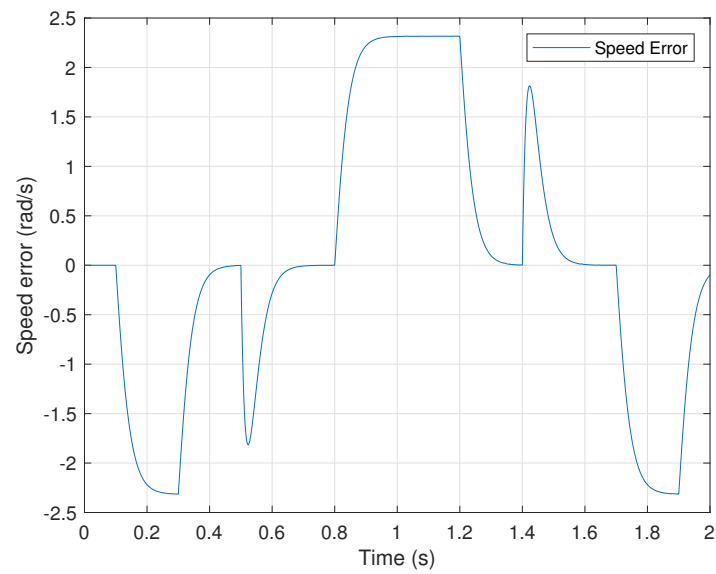

(c) DFOC-PI: Speed error

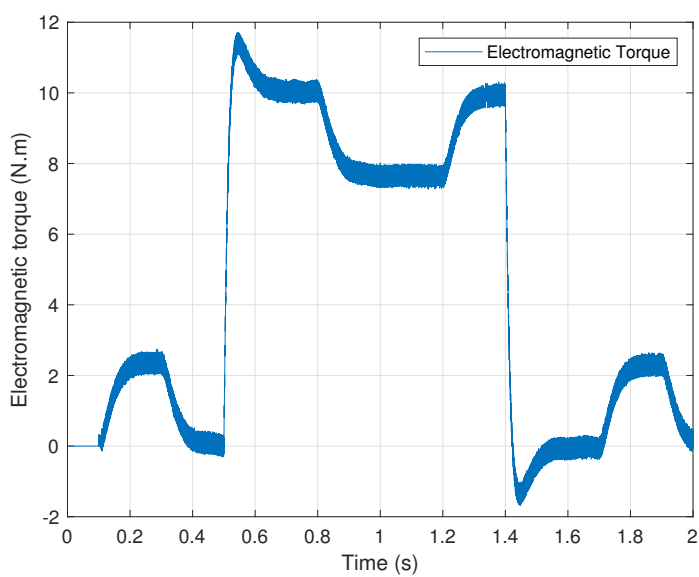

(e) DFOC-PI: Electromagnetic torque

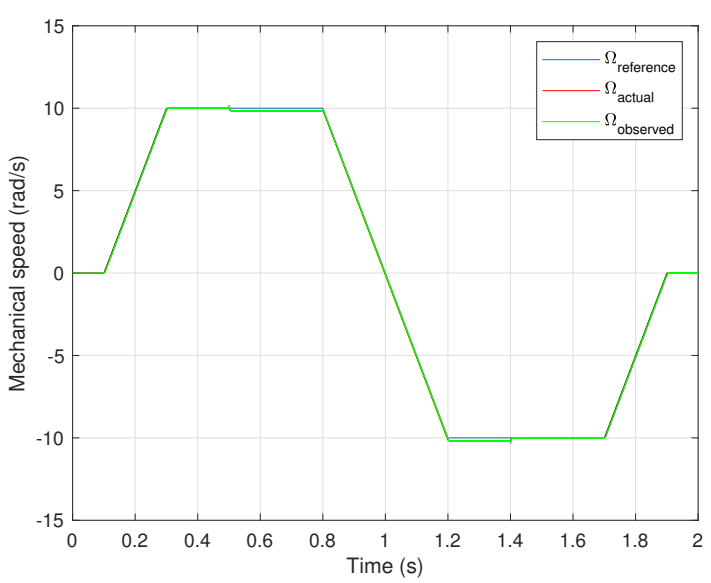

(b) DFOC-BSA: Mechanical speed

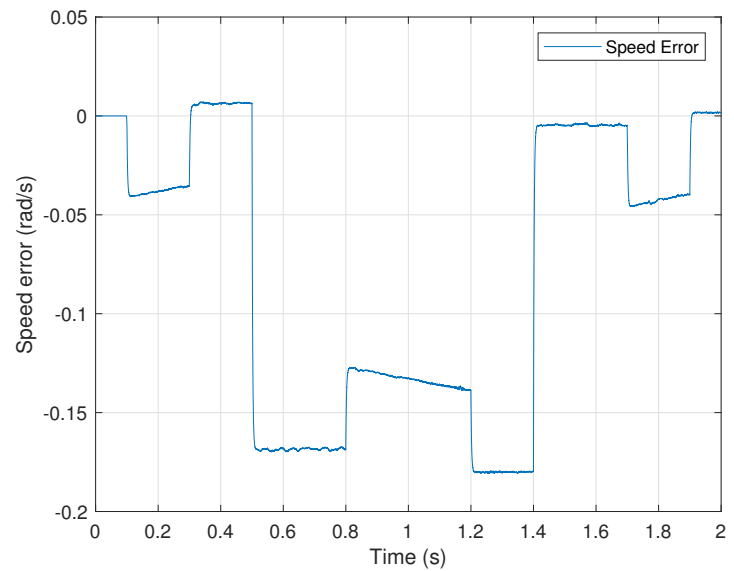

(d) DFOC-BSA: Speed error

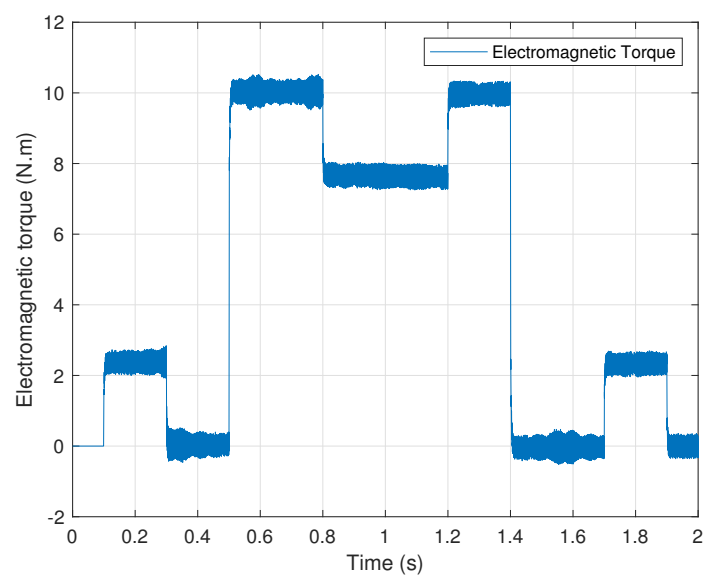

(f) DFOC-BSA: Electromagnetic torque 


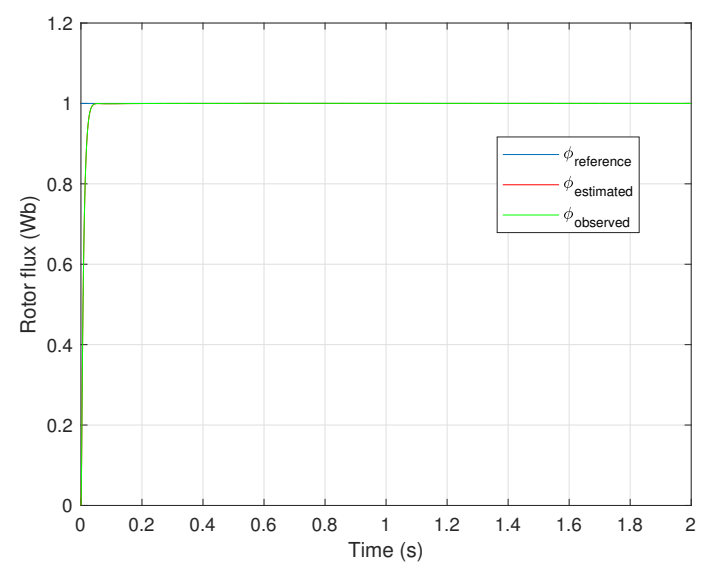

(g) DFOC-PI: Rotor flux

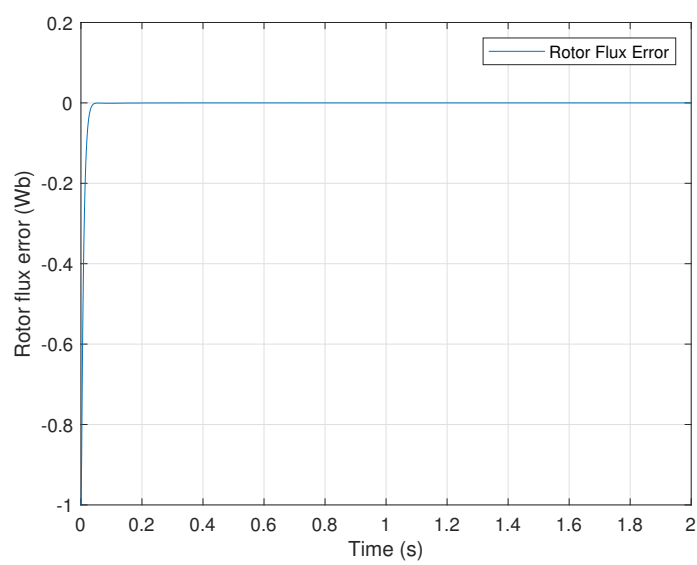

(i) DFOC-PI: Rotor flux error

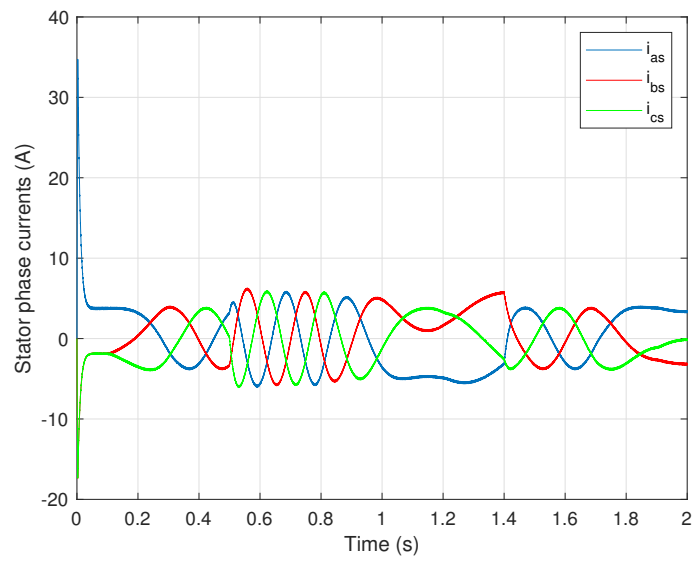

(k) DFOC-PI: Stator phase current

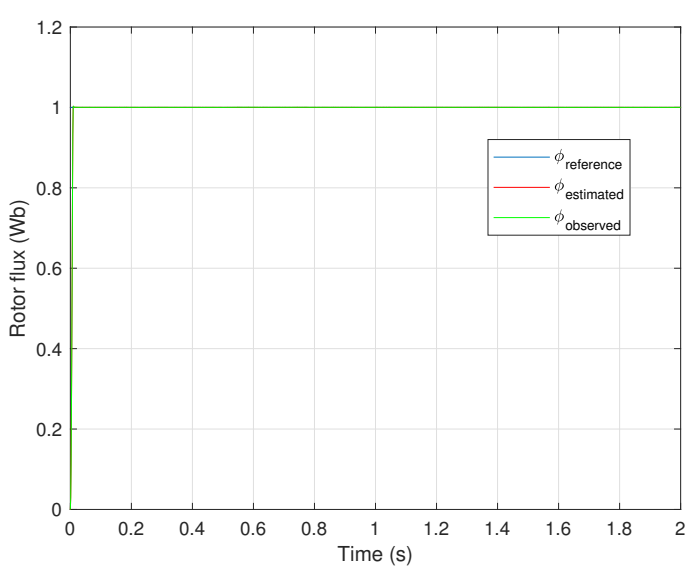

(h) DFOC-BSA: Rotor flux

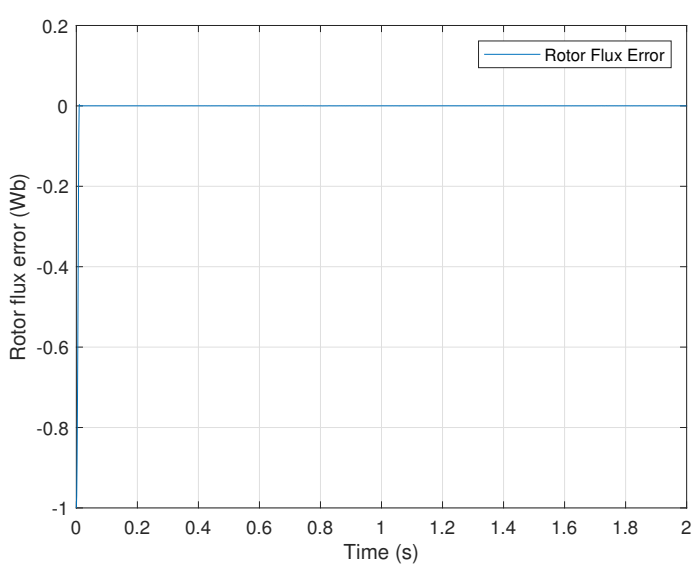

(j) DFOC-BSA: Rotor flux error

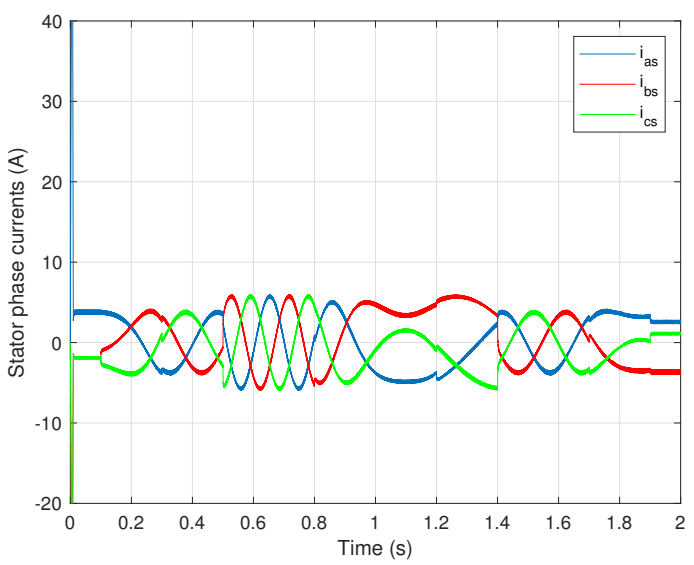

(l) DFOC-BSA: Stator phase current

Fig. 5. BSA vs PI: Operation at low-speed region 


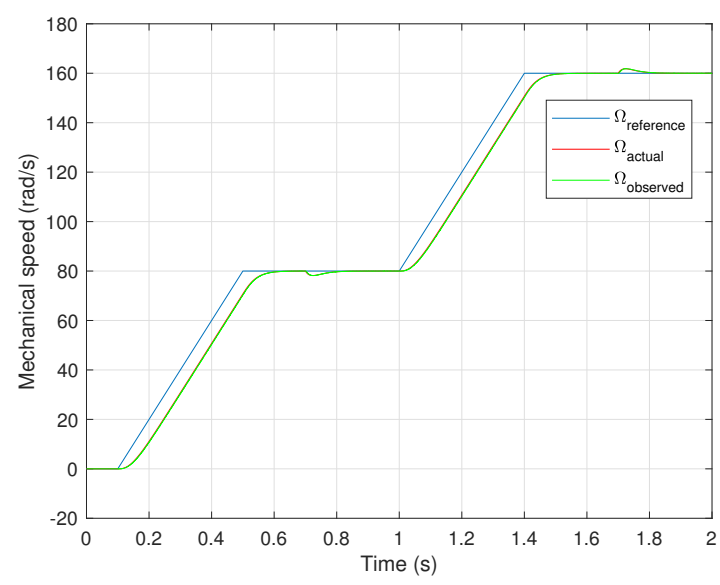

(a) DFOC-PI: Mechanical speed

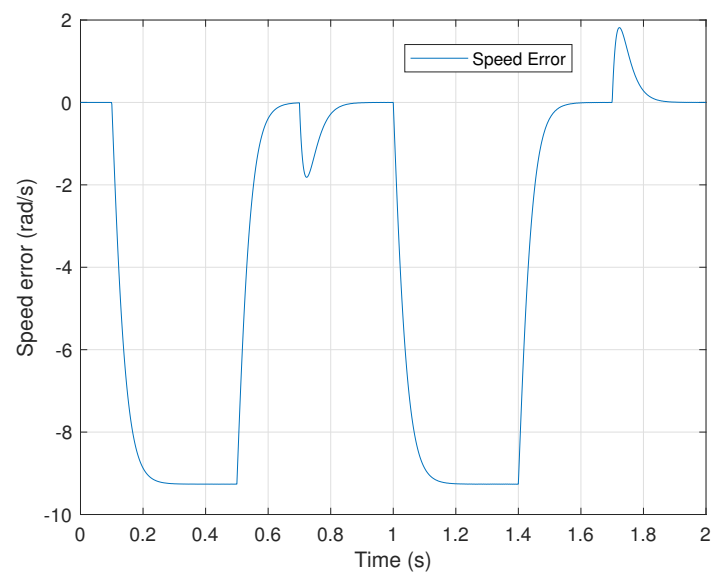

(c) DFOC-PI: Speed error

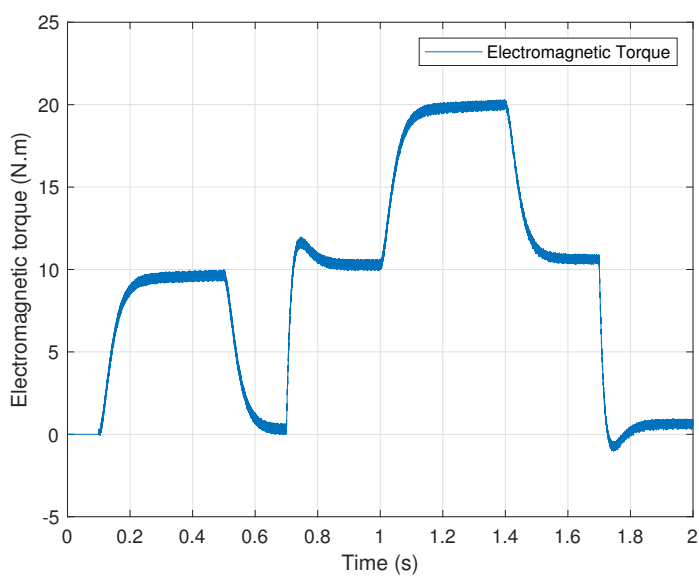

(e) DFOC-PI: Electromagnetic torque

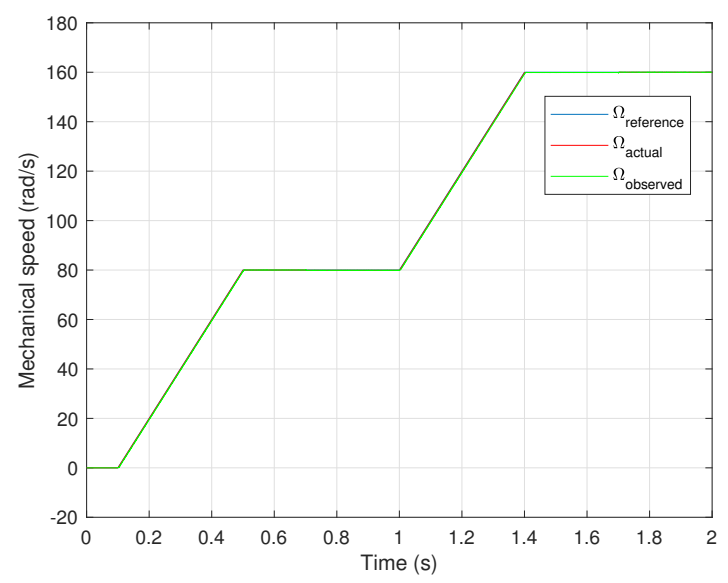

(b) DFOC-SMC: Mechanical speed

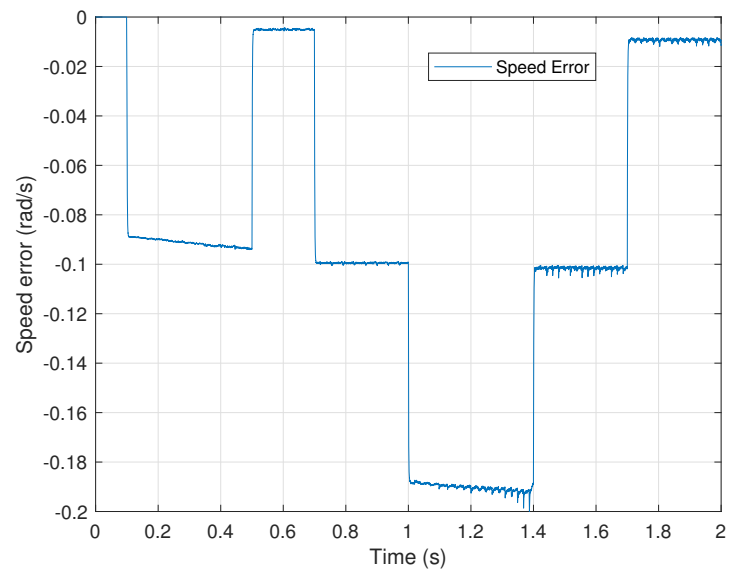

(d) DFOC-SMC: Speed error

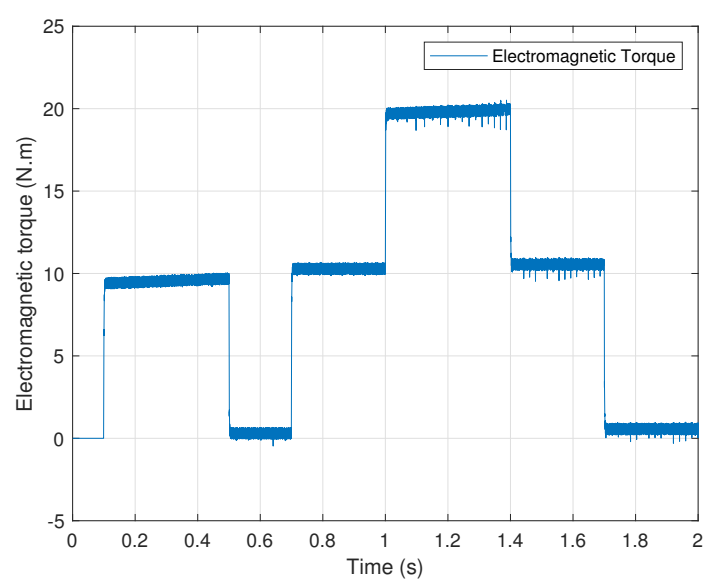

(f) DFOC-SMC: Electromagnetic torque 


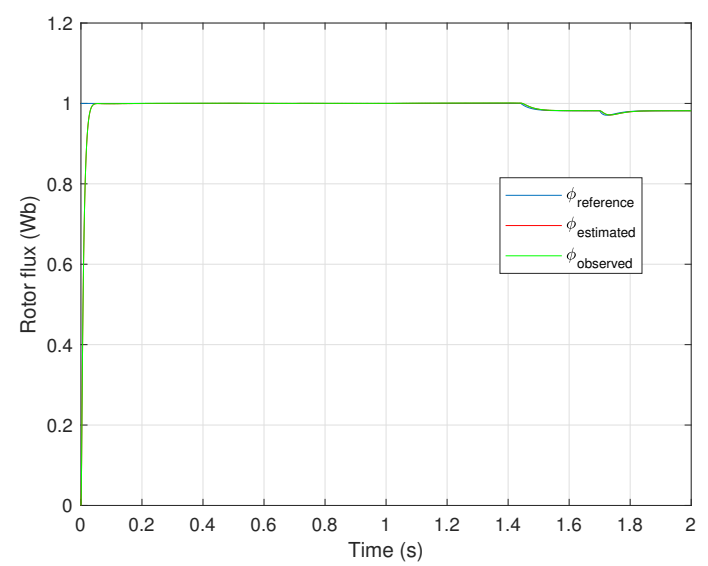

(g) DFOC-PI: Rotor flux

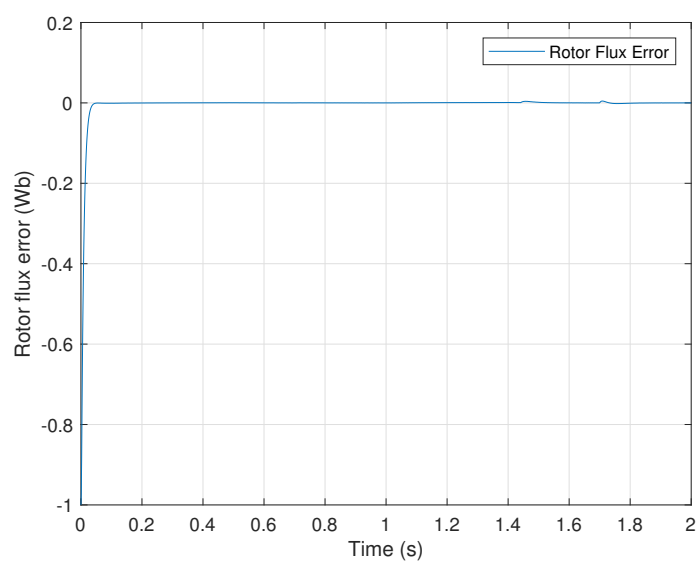

(i) DFOC-PI: Rotor flux error

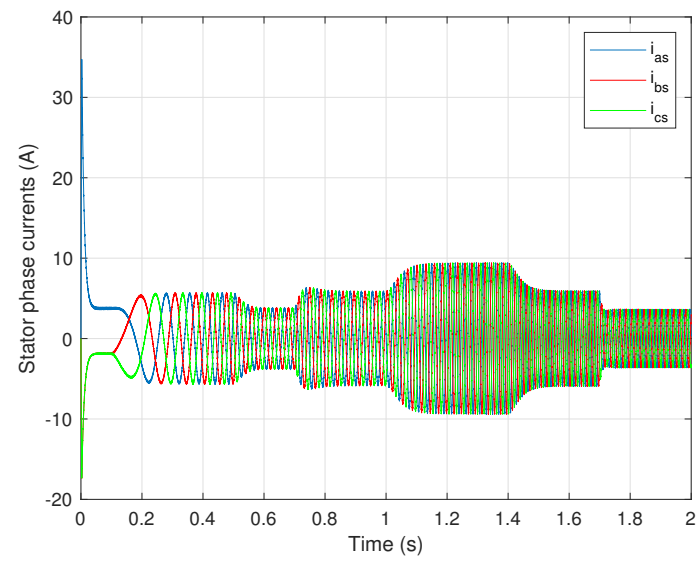

(k) DFOC-PI: Stator phase current

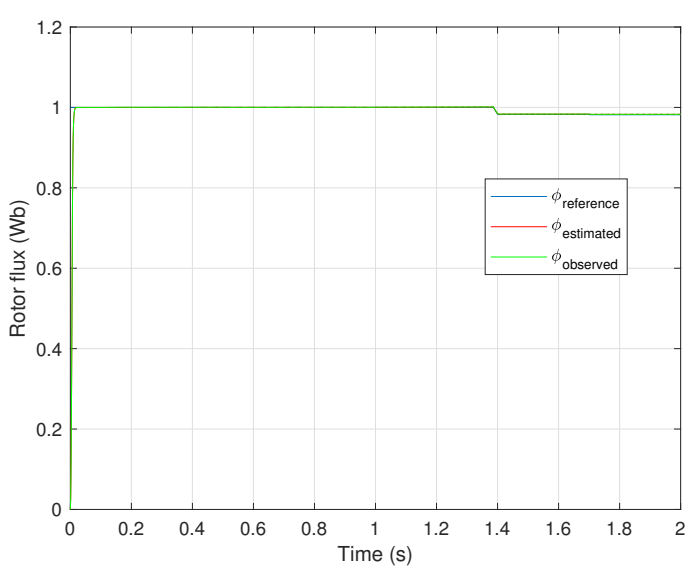

(h) DFOC-SMC: Rotor flux

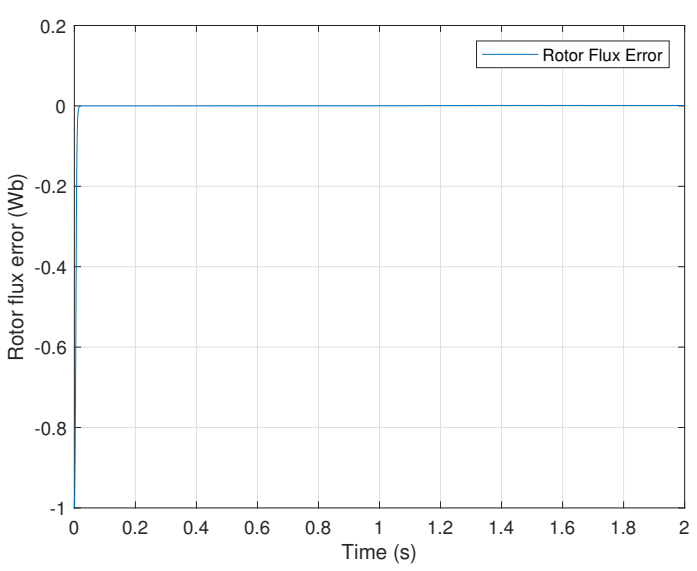

(j) DFOC-SMC: Rotor flux error

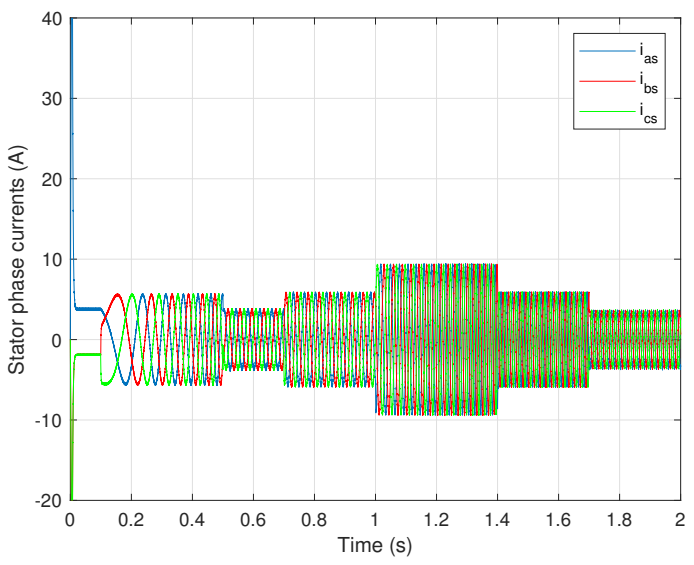

(I) DFOC-SMC: Stator phase current

Fig. 6. SMC vs PI: Operation at high-speed region 
2nd International Conference on Energy Conservation and Efficiency (ICECE), Oct. 2018, pp. 86-92, https://doi.org/10.1109/ECE.2018.8554980.

[3] O. A. Domínguez-Rámirez, C. A. Carrillo-Santos, L. E. Ramos-Velasco, J. C. Ramos-Fernández, M. A. Márquez-Vera, V. Parra-Vega, and A. Sanchez, "Online identification for auto-tuning PID based on wavelet neural networks: An experimental validation on an AC motor," in 2013 European Control Conference (ECC), Jul. 2013, pp. 4610-4615, https://doi.org/10.23919/ECC.2013.6669773.

[4] D. M. Dawson, J. Hu, and T. C. Burg, Nonlinear Control of Electric Machinery. Boca Raton: CRC Press, Sep. 2019, https://doi.org/10.1201/9780203745632.

[5] A. El Kharki, Z. Boulghasoul, L. Et-Taaj, Z. Kandoussi, and A. Elbacha, "Real Time Implementation of Backstepping Control for High Performances Induction Motor Drive," in 2019 4th World Conference on Complex Systems (WCCS), Apr. 2019, pp. 1-8, https://doi.org/10.1109/ICoCS.2019.8930745.

[6] M. Madark, A. Ba-Razzouk, E. Abdelmounim, and M. E. Malah, “A New Induction Motor Adaptive Robust Vector Control based on Backstepping," International Journal of Electrical and Computer Engineering (IJECE), vol. 7, no. 4, pp. 1983-1993, Aug. 2017, https://doi.org/10.11591/ijece.v7i4.pp1983-1993.

[7] K. Saad, K. Abdellah, H. Ahmed, and A. Iqbal, "Investigation on SVM-Backstepping sensorless control of five-phase open-end winding induction motor based on model reference adaptive system and parameter estimation," Engineering Science and Technology, an International Journal, vol. 22, no. 4, pp. 10131026, Aug. 2019, https://doi.org/10.1016/j.jestch.2019.02.008.

[8] M. S. Mahmoud and A. H. AlRamadhan, "Optimizing the Parameters of Sliding Mode Controllers for Stepper Motor through Simulink Response Optimizer Application," International Journal of Robotics and Control Systems, vol. 1, no. 2, pp. 209-225, Jul. 2021, https://doi.org/10.31763/ijrcs.v1i2.345.

[9] Y. Zahraoui, M. Akherraz, and S. Elbadaoui, “ Fuzzy Logic Speed Control and Adaptation MechanismBased Twelve Sectors DTC to Improve the Performance of a Sensorless Induction Motor Drive," International Journal on Electrical Engineering and Informatics, vol. 13, no. 3, pp. 508-529, 2021, https://doi.org/10.15676/ijeei.2021.13.3.1.

[10] Y. Zahraoui, M. Akherraz, and C. Fahassa, "Induction Motor Performance Improvement Using Twelve Sectors DTC and Fuzzy Logic Speed Regulation," WSEAS Transactions on Systems and Control, vol. 15, pp. 47-56, Mar. 2020, https://doi.org/10.37394/23203.2020.15.6.

[11] Y. Zahraoui, M. Akherraz, and S. Elbadaoui, "Improvement of Induction Motor State Observation: Extended Kalman Filter Versus Adaptive Luenberger Observer," WSEAS Transactions on Systems and Control, vol. 15, pp. 120-130, Apr. 2020, https://doi.org/10.37394/23203.2020.15.14.

[12] C. Fahassa, M. Akherraz, and Y. Zahraoui, "ANFIS-based hysteresis comparators with intelligent dual observer and speed controller of a direct torque control," International Journal of Powertrains, vol. 9, no. 1-2, pp. 150-170, Jan. 2020, https://doi.org/10.1504/IJPT.2020.108410.

[13] E. Zerdali, “A Comparative Study on Adaptive EKF Observers for State and Parameter Estimation of Induction Motor," IEEE Transactions on Energy Conversion, vol. 35, no. 3, pp. 1443-1452, Sep. 2020, https://doi.org/10.1109/TEC.2020.2979850.

[14] J. Laowanitwattana and S. Uatrongjit, "Estimation of induction motor states and parameters based on Extended Kalman Filter considering parameter constraints," in 2016 International Symposium on Power Electronics, Electrical Drives, Automation and Motion (SPEEDAM), Jun. 2016, pp. 755-760, https://doi. org/10.1109/SPEEDAM.2016.7525829.

[15] T. Roubache, S. Chaouch, and M. Naït-Saïd, "Comparative study between luenberger observer and extended kalman filter for fault-tolerant control of induction motor drives," Advances in Modelling and Analysis C, vol. 73, no. 2, Jun. 2018, https://doi.org/10.18280\%2Fama_c.730201.

[16] J. Faiz, V. Ghorbanian, and G. Joksimovic, Fault Diagnosis of Induction Motors. IET Digital Library, Aug. 2017, https://doi.org/10.1049/PBPO108E.

[17] V. Sousa Santos, J. J. Cabello Eras, A. Sagastume Gutierrez, and M. J. Cabello Ulloa, "Assessment of the energy efficiency estimation methods on induction motors considering real-time monitoring," Measurement, vol. 136, pp. 237-247, Mar. 2019, https://doi.org/10.1016/j.measurement.2018.12.080. 
[18] A. Zaafouri, C. B. Regaya, H. B. Azza, and A. Châari, "DSP-based adaptive backstepping using the tracking errors for high-performance sensorless speed control of induction motor drive," ISA Transactions, vol. 60, pp. 333-347, Jan. 2016, https://doi.org/10.1016/j.isatra.2015.11.021.

[19] N. T. Pham, "Novel nonlinear control structure for vector control of SPIM drive using BS PCH," International Journal of Power Electronics and Drive Systems (IJPEDS), vol. 11, no. 2, pp. 1099-1108, Jun. 2020, https://doi.org/10.11591/ijpeds.v11.i2.pp1099-1108.

[20] M. Salima, A. Loubna, and T. Riad, "A Global Stability of Linearizing Control of Induction Motor for PV Water Pumping Application,” International Journal of System Dynamics Applications (IJSDA), vol. 7, no. 3, pp. 31-56, Jul. 2018, https://doi.org/10.4018/IJSDA.2018070102.

[21] B. Aichi, M. Bourahla, and K. Kendouci, "Nonlinear Speed Control of Induction Motor by the Combination of Fuzzy-Sliding-Mode and Integral-Backstepping Controllers," in 2018 International Conference on Applied Smart Systems (ICASS), Nov. 2018, pp. 1-6, https://doi.org/10.1109/ICASS.2018.8652016.

[22] Y. Zahraoui, M. Akherraz, C. Fahassa, and S. Elbadaoui, "Induction Motor Harmonic Reduction using Space Vector Modulation Algorithm," Bulletin of Electrical Engineering and Informatics, vol. 9, no. 2, pp. 452-465, Apr. 2020, https://doi.org/10.11591/eei.v9i2.1682.

[23] M. Zerzeri, F. Jallali, and A. Khedher, "A Robust Nonlinear Control Based on SMC Approach for DoublyFed Induction Motor Drives Used in Electric Vehicles," in 2019 International Conference on Signal, Control and Communication (SCC), Dec. 2019, pp. 138-144, https://doi.org/10.1109/SCC47175.2019. 9116183.

[24] C. Djamila and Y. Miloud, "Performance Analysis of Adaptive Fuzzy Sliding Mode for Nonlinear Control of the Doubly Fed Induction Motor," Indonesian Journal of Electrical Engineering and Informatics (IJEEI), vol. 6, no. 4, pp. 436-447, Dec. 2018, https://doi.org/10.52549/ijeei.v6i4.605.

[25] A. Ammar, A. Bourek, and A. Benakcha, "Nonlinear SVM-DTC for induction motor drive using inputoutput feedback linearization and high order sliding mode control," ISA Transactions, vol. 67, pp. 428442, Mar. 2017, https://doi.org/10.1016/j.isatra.2017.01.010.

[26] Y. Zahraoui, M. Akherraz, C. Fahassa, and S. Elbadaoui, "Robust Control of Sensorless Sliding Mode Controlled Induction Motor Drive facing a Large Scale Rotor Resistance Variation," in Proceedings of the 4th International Conference on Smart City Applications, ser. SCA '19. New York, NY, USA: Association for Computing Machinery, Oct. 2019, pp. 1-6, https://doi.org/10.1145/3368756.3369036.

[27] M. Farza, M. M’Saad, T. Ménard, A. Ltaief, and T. Maatoug, "Adaptive observer design for a class of nonlinear systems. Application to speed sensorless induction motor," Automatica, vol. 90, pp. 239-247, Apr. 2018, https://doi.org/10.1016/j.automatica.2017.12.058.

[28] Y. Zahraoui, A. Bennassar, M. Akherraz, and A. Essalmi, "Indirect Vector Control of Induction Motor using an Extended Kalman Observer and Fuzzy Logic Controllers," in 2015 3rd International Renewable and Sustainable Energy Conference (IRSEC), Dec. 2015, pp. 1-6, https://doi.org/10.1109/IRSEC.2015. 7455046.

[29] Y. Zahraoui, C. Fahassa, M. Akherraz, and A. Bennassar, "Sensorless Vector Control of Induction Motor using an EKF and SVPWM Algorithm," in 2016 5th International Conference on Multimedia Computing and Systems (ICMCS), Sep. 2016, pp. 588-593, https://doi.org/10.1109/ICMCS.2016.7905584.

[30] Y. Zahraoui and M. Akherraz, Kalman Filtering Applied to Induction Motor State Estimation. IntechOpen, Jun. 2020, publication Title: Dynamic Data Assimilation - Beating the Uncertainties, https: //doi.org/10.5772/intechopen.92871. 